\title{
The Megafobia V-armchair Thrill-seeking Experience for Older Audiences - An Artistic Intervention at Age UK Barnet
}

\author{
Brendan Walker \\ Middlesex University \\ London, UK \\ studio@aerial.fm
}

\author{
Marianne Markowski \\ University of Greenwich \\ London, UK \\ a.m.markowski@gre.ac.uk
}

\begin{abstract}
This demonstration session presents the artistic and experimental explorations of using VR technology and a motion simulator to allow older people to experience the thrill of roller coasters.
\end{abstract}

Artistic intervention. Older people. VR-motion platform. Thrill-seeking.

\section{INTRODUCTION}

The number of people over 55 years old - the baby boomers - is growing in the UK and most parts of the world (ONS 2017). Usually people in the second half of their life span tend to be careful with physical activities to avoid the risk of getting injured considering the prolonged healing process due to age (Kim et al. 2015). At the same time some research argues that thrill-seeking behaviour is based on personality traits (Zuckerman 2007) and in fact there are exceptional thrill-seekers in advanced age such as 85 year old Surfer Barry McGuigan, 93 year old bungee jumper Mohr Keet and 100 year old sky diver Irene O'Shea (MacLaughlin 2016). However, the vast majority of baby boomers appear not to seek out opportunities to place their bodies into fast moving vehicles or constructions, where they do not have direct control over it.

The Megafobia V-armchair as an artistic intervention (Haseman 2007) intended to do exactly that, namely to bring older audiences the opportunity of a thrill-seeking experience but provided in a safe environment.

\section{CREATING THE MEGAFOBIA EXPERIENCE}

Professor Brendan Walker, working with the Universities of Nottingham and Middlesex, specialises in the creation of tailored emotional experiences. Together with Middlesex's technical team he created the $\mathrm{V}$-armchair. The $\mathrm{V}$-armchair consists of a VR headset showing a 360 video of the Megafobia rollercoaster ride and is combined with a wooden chair including a seat belt that is fixed to the motion platform emulating the moves of the roller coaster wagon.

Megafobia is an internationally renowned wooden roller coaster situated in Oakwood theme park in Wales and recently celebrated its 20th anniversary in 2016.

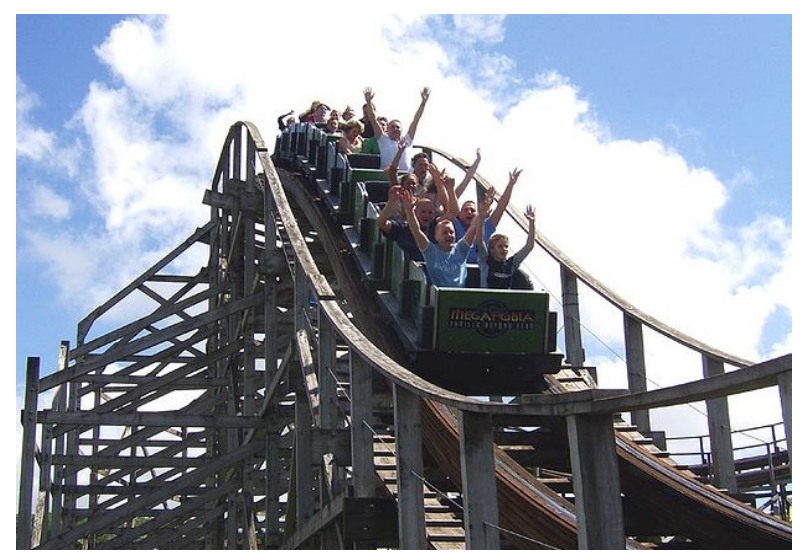

Figure 1: The megafobia rollercoaster

"Credit: WillMcC from the English-language Wikipedia, Licensed under CC-BY-SA 3.0"

The main motivation behind the intervention was to bring novel experiences to later life users who may feel limited by physical or psychological boundaries to seek out thrill experience by themselves and to create public and academic debate. Later life users present a particularly interesting case since they 
are a very diverse group. Many are likely to experience health related issues, which may stop them from pursuing thrilling experiences despite their character traits (Zuckerman 1971, 2007).

\subsection{The intervention at Age UK}

In collaboration with $\mathrm{Dr}$ Marianne Markowski, University of Greenwich, the intervention was held at Age UK Barnet. Those older participants, who volunteered to try the $\mathrm{V}$-armchair ride, were assessed for basic to health requirements (no pacemakers were allowed), informed about the ride and asked to give consent to the research. Each participant was given instructions on how to stop the 3-minute ride in case she or he felt unwell or wished to terminate it. The reactions by participants to the ride were explored in two ways, artistically and qualitatively. It was an artistic exploration because during the ride photographs of the participant's bodily expression were taken and qualitative since after the ride they were interviewed using a semi-structured questionnaire.

Due to a technical problem with the computer setup and subsequent loss of time, only five Age UK volunteers age 55 to 72 years were able to experience the $\mathrm{V}$-armchair ride. The feedback data is currently still being analysed.

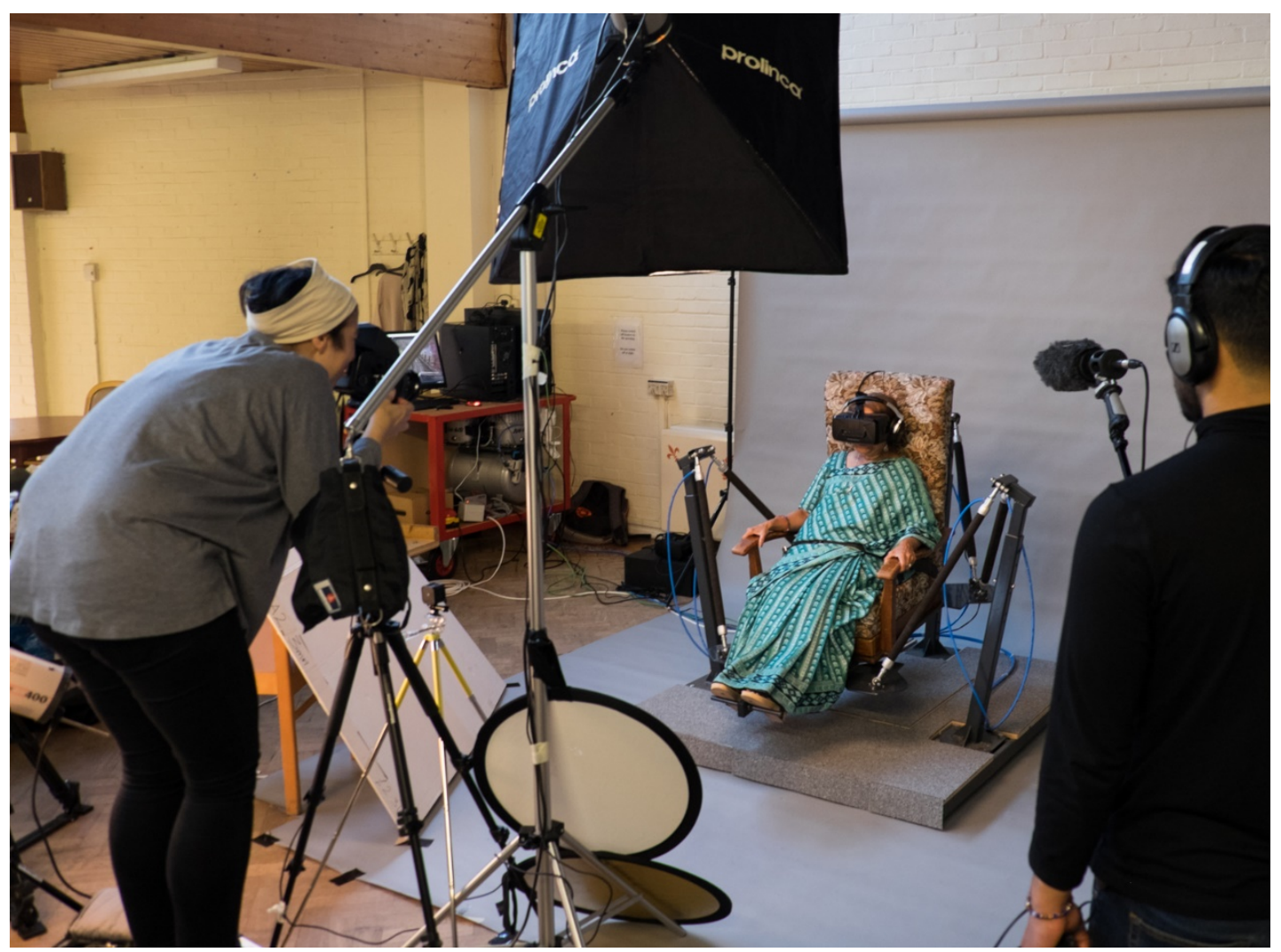

Figure 2: A volunteer experiencing the Megafobia V-armchair ride at Age UK Barnet whilst being photographed

\section{REFERENCES}

Barrett, E. and Bolt, B. (2007) Practice as Research: Approaches to Creative Arts Enquiry. I.B. Tauris

Kim, D. J., Mustoe, T., and Clark, R. A. (2015) Cutaneous wound healing in aging small mammals: A systematic review. Wound Repair and Regeneration. DOI: $10.1111 /$ wrr.12290

MacLaughlin, S. (2016) Sky-diving Granny celebrates turning 100 with history making jump while raising money for Motor Neurone Disease research. Daily Mail, Australia, 12 June.
http://www.dailymail.co.uk/news/article-3637382/A100-year-old-great-grandmother-oldest-person$\begin{array}{lll}\text { skydive-South-Australia.html } & \text { (retrieved on } 29\end{array}$ March 2017).

ONS (2017) Overview of the UK population: March 2017. Office of National Statistics, UK.

Zuckerman, M. (1971) Dimensions of sensation seeking. Journal of Consulting and Clinical Psychology, 36, pp. 45-52.

Zuckerman, M. (2007). Sensation seeking and risky behavior. Washington, DC: American Psychological Association. 